\title{
BOEKBESPREKING: \\ CHINESE CERAMICS AND THE MARITIME TRADE PRE-1700
}

Brian McElney is bekend als directeur van het Asian Art Museum in Bath (geopend in 1993). Hij heeft een grote belangstelling voor verschillende aspecten van de Chinese kunst, vooral voor jade en keramiek. Hij ontwikkelde zijn kennis hierover in Hong Kong waar hij een advocatenkantoor had en waar hij met een bijzondere 'snuffelneus' uitstekende stukken wist te vinden op markten en bij antiquairs. Hij kan eindeloos vertellen over waar hij een bepaald object voor een 'prikkie' heeft gekocht dat nu duizenden ponden waard is.

Zijn museum in Bath toont het resultaat van McElney's kennis en speurzin en elke keer dat hij een tentoonstelling houdt, bestaat deze volledig uit stukken van de eigen collectie. Een van zijn grote passies is keramiek die uit China werd geëxporteerd. McElney heeft hierover diverse artikelen geschreven en een van zijn laatste, gepubliceerd in 1999 in het tijdschrift van het museum, was duidelijk een voorproef van de catalogus die de huidige tentoonstelling begeleidt. Daarin schreef hij dat recente archeologische ontdekkingen meer duidelijkheid bieden over de datering van 'non imperial ceramics'. Hiermee bedoelt hij porselein dat tot nu meestal 'provinciaals' werd genoemd en waarover dankzij de berging van verschillende scheepswrakken inderdaad meer duidelijk is geworden.

In het voorwoord van de catalogus schrijft McElney dat hij een overzicht wil geven van de geschiedenis van de Chinese overzeese handel omdat dat nog nergens is gedaan. Hij doet dat in de vorm van een aantal 'essays' die een chronologische geschiedenis weergeven. Het eerste hoofdstuk begint met de filosofische achtergrond: de Chinese visie op de handel met het buitenland en vervolgens hoe de handel per schip maar ook via de Zijderoute is ontstaan. In het tweede hoofdstuk worden Chinese decreten behandeld die bepalend zijn geweest voor deze handel. Een aantal hiervan zijn bekend, zoals het decreet uit 1371 dat Chinezen verbood om het land te verlaten en vooral: te handelen met andere landen. Een ander bekend decreet, uit 1436, maakte een einde aan het bouwen van de enorme schepen die onder de beroemde admiraal Zheng He de wereld over gingen. Vooral interessant is het decreet uit $\mathbf{1 5 2 5}$ met het bevel dat alle schepen met meer dan twee masten moesten worden vernietigd. Dit had als gevolg dat tussen 1525-1560 weinig keramiek in landen zoals de Filippijnen is terechtgekomen. Andere decreten die McElney noemt gaan over het verbod om bepaalde motieven op porselein te schilderen, zoals het verbod uit 1438 op de vervaardiging van porselein met blauwe decoraties in navolging van het keizerlijk porselein.

Het derde hoofdstuk geeft een overzicht over de handel door de Arabische landen. Hij noemt onder meer het incident dat in 878 in Guangzhou plaatsvond waarbij zo'n 120.000 buitenlanders (joden, moslims en christenen) werden gedood. Dit had als gevolg dat de islamitische handelaren elders huncess 


\section{Afbeelding 1}

Kom, porselein gedecoreerd in onderglazuur

blauw, d. $14 \mathrm{~cm}$, China, 1560-1590, uit het besproken boek.

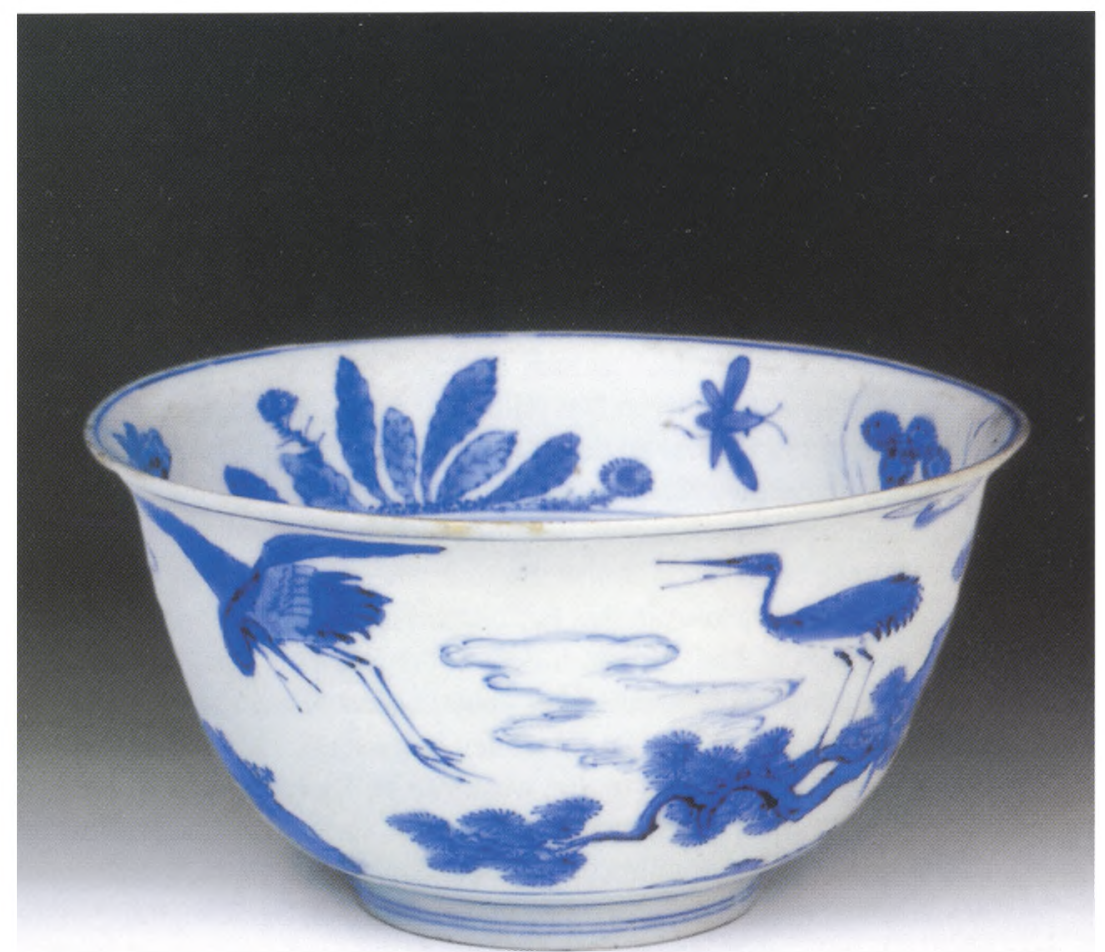

handelspost gingen opzetten en de Chinezen zelf hun handelswaren over zee aanvoerden. Vervolgens behandelt McElney de vondsten op Sri Lanka uit de Tang- (618-906) en Song-perioden (960-1279). De overzeese handel door de Chinezen zelf wordt verder in het volgende hoofdstuk beschreven. Hoewel de meeste informatie in deze hoofdstukken niet nieuw is, biedt McElney wel een bruikbaar overzicht van de op dit moment beschikbare informatie.

Ik vind vooral hoofdstuk 5 interessant omdat het de handel in keramiek vanuit Fujian uitvoerig beschrijft. Deze provincie met de belangrijke havensteden Fuzhou en Quanzhou is vrij verwaarloosd geweest in de geschiedschrijving van de keramiek, terwijl het zo'n belangrijke rol speelde vooral wat betreft de handel naar de Ryukyu eilanden en Japan. Fuzhou was de officiële haven van waaruit handel mocht worden gedreven met deze eilanden waar heel veel keramiek uit de $15^{\mathrm{e}}$ eeuw is gevonden. Een uitstekende bijdrage aan deze catalogus is dan ook een apart hoofdstuk, geschreven door de Chinese archeoloog Li Jian'an van het Institute of Archaeology van het Fujian Museum. Hij geeft een goed overzicht van de vondsten uit productieplaatsen die de laatste jaren zijn gevonden in de provincie Fujian. Vooral ovenplaatsen uit de Song- en Yuan-dynastieën (1269-1368) zijn onderzocht waarbij restanten van keramiek zijn gevonden die hetzelfde zijn als die op diverse plaatsen overzee. $\mathrm{Zo}$ is in 2003 celadon en qingbai-keramiek op allerlei plekken tevoorschijn gekomen terwijl men dacht dat deze alleen gemaakt werden in het gebied van de Tong'an ovens.

Gelukkig zijn sinds 1987 ook Chinese archeologen actief die een belangrijke bijdrage aan de geschiedenis van de keramiekhandel leveren. Vanaf 2000 hebben zij diverse scheepswrakken vastgelegd en $n_{F}$ sinds $2002_{2}$ duiken zij $_{20}$ 11:44:11AM $_{2}$ continu bij de Chuanshan en Xisha eilanden. 
Vanaf hoofdstuk 6 brengen de vermelde chronologische feiten niets nieuws, omdat deze over de Europese handel van Chinees porselein gaan. Hij presenteert ook hier (zeker niet voor de eerste keer) zijn chronologische indeling van het kraakporselein, maar maakt daarbij helaas een aantal fouten.

Eerlijkheidshalve moet worden gezegd dat McElney een van de eersten was (na Hessel Miedema in 1964) om überhaupt het kraakporselein uitgebreid te beschrijven.' Maar door steeds meer archeologische vondsten, met name in lingdezhen zelf, is de indeling van kraak-motieven die hij toen maakte en die door Maura Rinaldi in haar standaardwerk is overgenomen, nu toch echt wel achterhaald. ${ }^{2}$ Bovendien rekent hij ten onrechte zijn eerste drie groepen tot het kraak hoewel zij duidelijk afkomstig zijn uit de tijd vóór de productie van kraaikommen, klapmutsen en borden met een platte rand met de indeling van panelen typisch voor het kraakmotief.

Op de conferentie over Portugese scheepswrakken in Mossel Bay (Zuid-Afrika) in augustus jongstleden hebben wij hierover uitgebreid gediscussieerd. Het bewijs dat de Portugezen vóór 1600 geen porselein met in de rand een indeling in kraak-panelen hebben vervoerd, kan worden gebaseerd op de vondsten uit Portugese wrakken langs de oostkust van Zuid-Afrika. Porselein dat is aangespoeld uit het wrak van de Santo Alberto, gezonken in 1593, heeft duidelijk geen kraakmotief. Het eerste wrak waaruit porselein met dit motief langs deze kust is gevonden, is dat van de Santo Espirito uit 1608. Maar inmiddels hebben de vondsten uit de San Diego uit 1600 al bewezen dat porselein met kraakmotieven in die periode voor de export werd gemaakt. De archeologische bewijzen uit Jingdezhen zijn tot nu nog niet gepubliceerd, maar hierin zal hopelijk snel verandering komen.

McElney heeft met deze catalogus een interessante bijdrage geleverd aan de geschiedenis van de maritieme handel van China. Het is echter jammer dat dit niet wetenschappelijk is onderbouwd: hij verwijst nauwelijks naar bronnen en zijn bibliografie is dermate summier dat het te verwaarlozen is. Gelukkig compenseert het hoofdstuk van bovengenoemde archeoloog Li Jian'an deze tekortkomingen. Hij heeft echt een indrukwekkende bijdrage geleverd en hopelijk zullen andere deskundigen uit China meer informatie geven over de vondsten uit dat land die bepalend zijn om tot een datering te komen van Chinees porselein dat over de hele wereld verspreid terecht is gekomen. De tentoonstelling zal na Bath in juni 2007 in Hong Kong te zien zijn en McElney hoopt daar een symposium over dit onderwerp te organiseren. De bijdragen van de Chinese archeologen kunnen dan hopelijk eindelijk de westerse visies over de maritieme handel van Chinese keramiek corrigeren en aanvullen.

- Brian McElney

Chinese Ceramics and the Maritime Trade Pre-1700

The Museum of East Asian Art, Bath, 2006

Gebonden, 188 pagina's 112 kleurenillustraties

ISBN 1897734131

\section{Noten}

1. H. Miedema, Kraakporselein en Overgangsgoed, Leeuwarden, 1964.

2. M. Rinaldi, Kraak Porcelain; a moment in the history of trade, Londen, 1989 